\title{
Comparison of shear bond strengths of different types of denture teeth to different denture base resins
}

\author{
Vladimir Prpići1*, Zdravko Schauperl², Domagoj Glavina ${ }^{3}$, Amir Ćatić ${ }^{4}$, Samir Čimićc \\ ${ }^{1}$ School of Dental Medicine, University of Zagreb, Zagreb, Croatia \\ 2Department of Materials, Faculty of Mechanical Engineering and Naval Architecture, University of Zagreb, Zagreb, Croatia \\ ${ }^{3}$ Department of Pediatric and Preventive Dentistry, School of Dental Medicine, University of Zagreb, Zagreb, Croatia \\ ${ }^{4}$ Department of Prosthodontics, School of Dental Medicine, University of Zagreb, Zagreb, Croatia
}

\begin{abstract}
PURPOSE. To determine the shear bond strengths of different denture base resins to different types of prefabricated teeth (acrylic, nanohybrid composite, and cross-linked) and denture teeth produced by computeraided design/computer-aided manufacturing (CAD/CAM) technology. MATERIALS AND METHODS. Prefabricated teeth and CAD/CAM (milled) denture teeth were divided into 10 groups and bonded to different denture base materials. Groups 1-3 comprised of different types of prefabricated teeth and cold-polymerized denture base resin; groups 4-6 comprised of different types of prefabricated teeth and heat-polymerized denture base resin; groups 7-9 comprised of different types of prefabricated teeth and CAD/CAM (milled) denture base resin; and group 10 comprised of milled denture teeth produced by CAD/CAM technology and CAD/CAM (milled) denture base resin. A universal testing machine was used to evaluate the shear bond strength for all specimens. One-way ANOVA and Tukey post-hoc test were used for analyzing the data $(\alpha=.05)$. RESULTS. The shear bond strengths of different groups ranged from $3.37 \pm 2.14 \mathrm{MPa}$ to $18.10 \pm 2.68 \mathrm{MPa}$. Statistical analysis showed significant differences among the tested groups $(P<.0001)$. Among different polymerization methods, the lowest values were determined in cold-polymerized resin. There was no significant difference between the shear bond strength values of heat-polymerized and CAD/CAM (milled) denture base resins. CONCLUSION. Different combinations of materials for removable denture base and denture teeth can affect their bond strength. Cold-polymerized resin should be avoided for attaching prefabricated teeth to a denture base. CAD/CAM (milled) and heat-polymerized denture base resins bonded to different types of prefabricated teeth show similar shear bond strength values. [J
\end{abstract}

Adv Prosthodont 2020;12:376-82]

KEYWORDS: Complete denture; Digital denture; Acrylics; Prefabricated teeth

\section{INTRODUCTION}

Debonding of a tooth from a denture base of a complete

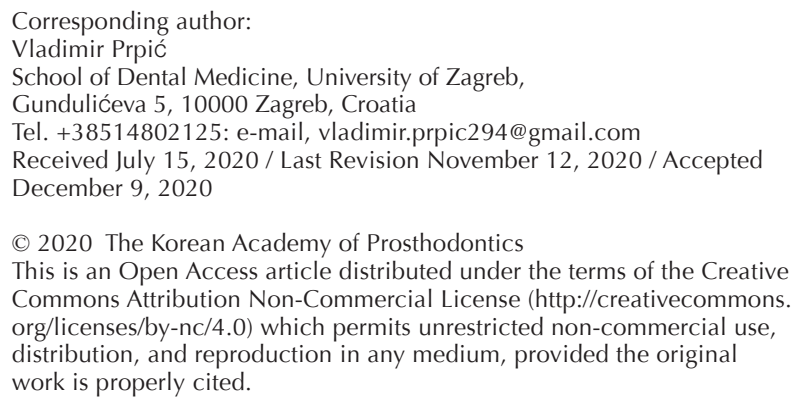
Commons Attribution Non-Commercial License (http://creativecommons. org/licenses/by-nc/4.0) which permits unrestricted non-commercial use, distribution, and reproduction in any medium, provided the original work is properly cited.

This work was supported, in part, by the University of Zagreb's "Diagnostic and Therapy of Craniomandibular Dysfunctions" scientific support. or partial removable denture is the most common clinical situation requiring subsequent repair. ${ }^{1}$ According to studies, $30 \%$ of all denture repairs are caused by debonding of prefabricated teeth. ${ }^{2-4}$ The problem is even greater with implantsupported overdentures because their higher chewing capacity increases the risk of tooth detachment from the overdenture base. $^{5}$

Denture base resin and prefabricated teeth differ in a structure and are fabricated separately. Separated fabrication processes are considered to be one of the main factors that can lead to tooth failure, especially in the anterior portion of a removable denture. ${ }^{6,7}$ The denture base resin that has been used most frequently in dental medicine is polymethylmethacrylate (PMMA). ${ }^{7}$ Findings related to the bond strength between denture base materials and artificial teeth 
vary. ${ }^{8-16}$ As some studies have already reported, different types of prefabricated teeth also showed differences in the shear bond strength. ${ }^{4,17}$

Advancements in technology have ensured digital methods for denture base fabrication (computer-aided design/ computer-aided manufacturing [CAD/CAM]), including subtractive (milling) and additive technologies (three-dimensional [3D] printing). ${ }^{18-21}$ Digital techniques allow fabrication of a denture base in one block, and they have the ability to attach prefabricated teeth or CAD/CAM (milled) teeth with an adequate adhesive or to bond them using cold or heat polymerization (conventional approach). ${ }^{19}$ Most manufacturers suggest use of adhesive as a better option. ${ }^{22,23}$ The literature findings about the bond strength between digitally produced denture base resins and different types of artificial teeth (including teeth produced with CAD/CAM technology) are scarce. To the authors' knowledge, there are only two studies which have included digitally produced denture bases and different types of denture teeth. ${ }^{9,24}$ However, these studies did not include CAD/CAM (milled) denture teeth.

Shear bond strength testing is the most widely used type of testing ${ }^{25}$ for analyzing the bond strength between denture base resins and artificial teeth. ${ }^{13-17,26}$ The aim of this study was to examine the shear bond strength of different types of prefabricated teeth (acrylic, nanohybrid composite, and cross-linked teeth) and CAD/CAM (milled) denture teeth to CAD/CAM (milled), cold-polymerized, and heatpolymerized denture base resins. The null hypothesis was that different materials would have similar shear bond strength values.

\section{MATERIALS AND METHODS}

Eighty specimens were prepared from three different types of prefabricated teeth (acrylic [SR Orthotyp S PE, Ivoclar Vivadent, Schaan, Liechtenstein], nanohybrid composite [Phonares II Typ, Ivoclar Vivadent, Schaan, Liechtenstein], cross-linked [SR Orthotyp DCL, Ivoclar Vivadent, Schaan, Liechtenstein]), and one type of milled CAD/CAM denture teeth (SR Vivodent CAD, Ivoclar Vivadent, Schaan, Liechtenstein). They were combined with three types of denture base resins-cold-polymerized acrylics (ProBase Cold, Ivoclar Vivadent, Schaan, Liechtenstein), heat-polymerized acrylics (ProBase Hot, Ivoclar Vivadent, Schaan, Liechtenstein), and CAD/CAM (milled) denture base resin (IvoBase CAD, Ivoclar Vivadent, Schaan, Liechtenstein). A list of groups, name of materials, and the manufacturer is shown in Table 1 . The specimens were divided into 10 groups, and each group had eight specimens. Fig. 1 and Fig. 2 show diagrams of specimens.

Specimen preparation was similar to that in a previous research. ${ }^{1,26,27}$ Each prefabricated tooth was immersed in a colorless cold-polymerized acrylate (Clarocit Kit, Struers Co., Ballerup, Denmark) in a plastic mold (FlexiForm round, Struers Co., Ballerup, Denmark) according to the manufacturer's instructions. After cooling, specimens (acrylic cylinder with immersed tooth) were carefully removed from the plastic molds. The ridge lap surface of each tooth was exposed with a water cutting machine (IsoMet 1000, Buehler, Lake Bluff, IL, USA). No other treatment of the ridge lap surface of teeth was used. A metallic mold was employed to create silicone samples (Optosil Comfort Putty,

Table 1. Groups, name of materials and manufacturer

\begin{tabular}{|c|c|c|}
\hline Group & Name of materials & Manufacturer \\
\hline $\begin{array}{l}\text { Cold-polymerized denture base resin and } \\
\text { acrylic teeth }\end{array}$ & Probase cold and SR Orthotyp S PE & Ivoclar Vivadent, Schaan, Liechtenstein \\
\hline $\begin{array}{l}\text { Cold-polymerized denture base resin and } \\
\text { nanohybrid composite teeth }\end{array}$ & Probase cold and Phonares II Typ & Ivoclar Vivadent, Schaan, Liechtenstein \\
\hline $\begin{array}{l}\text { Cold-polymerized denture base resin and } \\
\text { cross-linked teeth }\end{array}$ & Probase cold and SR Orthotyp DCL & Ivoclar Vivadent, Schaan, Liechtenstein \\
\hline $\begin{array}{l}\text { Heat-polymerized denture base resin and } \\
\text { acrylic teeth }\end{array}$ & Probase hot and SR Orthotyp S PE & Ivoclar Vivadent, Schaan, Liechtenstein \\
\hline $\begin{array}{l}\text { Heat-polymerized denture base resin and } \\
\text { nanohybrid composite teeth }\end{array}$ & Probase hot and Phonares II Typ & Ivoclar Vivadent, Schaan, Liechtenstein \\
\hline $\begin{array}{l}\text { Heat-polymerized denture base resin and } \\
\text { cross-linked teeth }\end{array}$ & Probase hot and SR Orthotyp DCL & Ivoclar Vivadent, Schaan, Liechtenstein \\
\hline $\begin{array}{l}\text { CAD/CAM (milled) denture base resin and } \\
\text { acrylic teeth }\end{array}$ & IvoBase CAD and SR Orthotyp S PE & Ivoclar Vivadent, Schaan, Liechtenstein \\
\hline $\begin{array}{l}\text { CAD/CAM (milled) denture base resin and } \\
\text { nanohybrid composite teeth }\end{array}$ & IvoBase CAD and Phonares II Typ & Ivoclar Vivadent, Schaan, Liechtenstein \\
\hline $\begin{array}{l}\text { CAD/CAM (milled) denture base resin and } \\
\text { cross-linked teeth }\end{array}$ & IvoBase CAD and SR Orthotyp DCL & Ivoclar Vivadent, Schaan, Liechtenstein \\
\hline $\begin{array}{l}\text { CAD/CAM (milled) denture base resin and } \\
\text { CAD/CAM (milled) denture teeth }\end{array}$ & IvoBase CAD and SR Vivodent CAD & Ivoclar Vivadent, Schaan, Liechtenstein \\
\hline
\end{tabular}




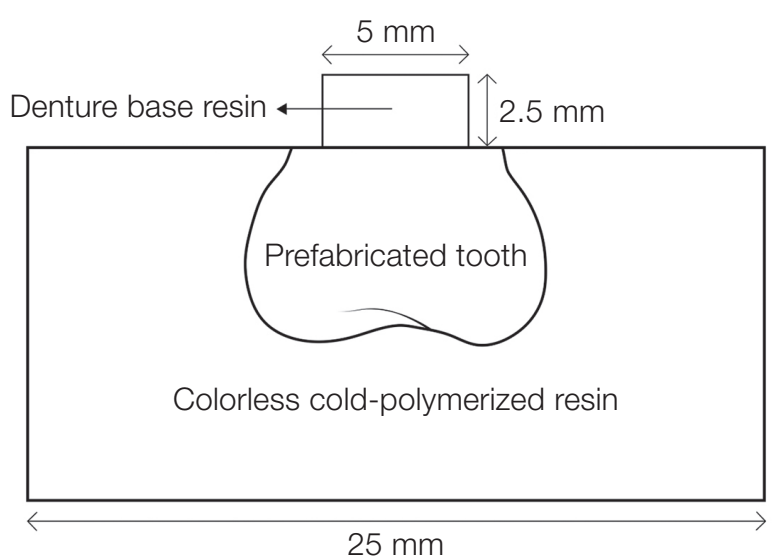

Fig. 1. Diagram of the specimens for groups 1-9.

Kulzer, Hanau, Germany) with a $25.0 \mathrm{~mm}$ diameter $\times 2.5$ $\mathrm{mm}$ height. Each sample had a circular opening in the center, with a $5.0 \mathrm{~mm}$ diameter $\times 2.5 \mathrm{~mm}$ height, for preparation of the denture base resin cylinders. Silicon samples were fixed with an instant adhesive (Loctite, Henkel, Düsseldorf, Germany) on the exposed surface of the acrylic cylinders, which comprised of the embedded prefabricated tooth. The circular opening in silicone was filled with wax before the flasking procedure to secure space for heatpolymerized acrylics. Specimens of prefabricated teeth and heat-polymerized cylinders were obtained via the flasking procedure. The lower part of the flask was filled with gypsum, and the specimen was immersed. The gypsum was coated with separating medium (Separating Fluid, Ivoclar Vivadent, Schaan, Liechtenstein), the upper part of the flask was positioned, and the second layer of gypsum was placed, followed by complete closure of the flask. After gypsum induration, the flask was opened, and the wax was removed. The packing stage followed, and polymerization was carried out according to the manufacturer's instructions in an appropriate polymerization unit (EWL Typ 5509, Kavo, Biberach, Germany). Each flask was left for cooling at room temperature. Then, the specimens were carefully deflasked and cleaned. Cold-polymerized cylinders were obtained in a similar manner by inserting cold-polymerized acrylics into a circular opening of the silicon mold. Following the manufacturer's instructions, polymerization was carried out in a pressure device (Ivomat IP2, Ivoclar Vivadent, Schaan, Liechtenstein) at $40^{\circ} \mathrm{C}$ and at 6 bar pressure for 15 minutes. CAD/CAM cylinders $(5.0 \mathrm{~mm}$ diameter $\times 2.5 \mathrm{~mm}$ height) were constructed (Netfabb Premium 2019, Autodesk, San Rafael, CA, USA) and saved as a standard tessellation language (STL) file. A milling machine (Ceramill Mikro 5X, Amann Girrbach, Koblach, Austria) was used to obtain CAD/CAM cylinders (IvoBase CAD) according to the attained STL file. The cylinders were glued with a PMMA-based bonding material (IvoBase CAD Bond Kit 10, Ivoclar Vivadent, Schaan, Liechtenstein) to the

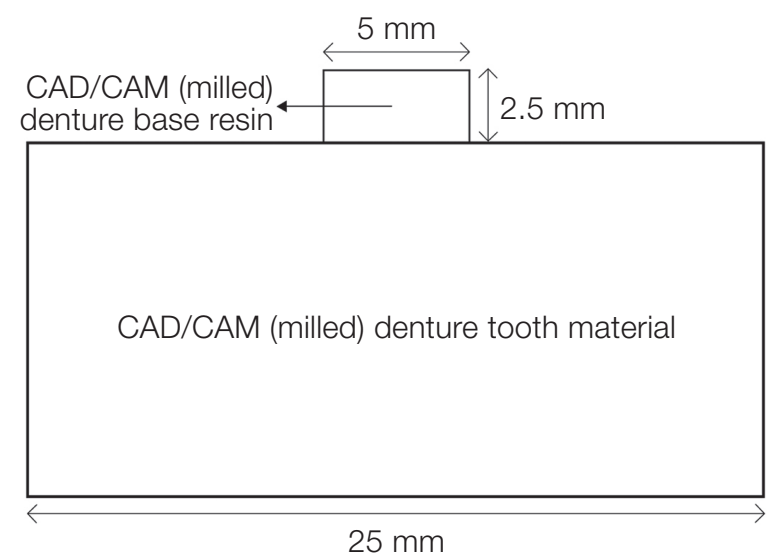

Fig. 2. Diagram of the specimens for group 10 .

exposed surface of the teeth (SR Orthotyp S PE; Phonares II Typ; SR Orthotyp DCL; and SR Vivodent CAD). CAD/ CAM tooth cylinders of $25.0 \mathrm{~mm}$ diameter $\times 12.0 \mathrm{~mm}$ height were milled from CAD/CAM discs (SR Vivodent CAD, Ivoclar Vivadent, Schaan, Liechtenstein) using the same software (Netfabb Premium 2019) and the milling machine (Ceramill Mikro 5X). In the center of each CAD/ CAM (milled) tooth cylinder, a CAD/CAM (milled) denture base resin cylinder $(5.0 \mathrm{~mm}$ diameter $\times 2.5 \mathrm{~mm}$ height $)$ was glued with a bonding agent (IvoBase CAD Bond Kit 10). The specimens appeared like denture teeth embedded in acrylic (first mandibular molars) bonded to denture base resin cylinders with $5.0 \mathrm{~mm}$ diameter $\times 2.5 \mathrm{~mm}$ height. ${ }^{1}$ All specimens were stored in distilled water at $37^{\circ} \mathrm{C}$ for 48 hours before testing.

The shear bond strength between denture base resins and prefabricated teeth and teeth produced by CAD/CAM (milled) was determined using a universal shear bond strength testing machine (model LRX, Lloyd Instruments, Fareham, Great Britain) at a $1 \mathrm{~mm} / \mathrm{min}$ crosshead speed. The load at fracture was recorded and presented by the software of the testing machine (Nexygen, Lloyd Instruments, Fareham, Great Britain). Failure was classified by using a stereomicroscope (Olympus SZX10, Olympus, Tokyo, Japan) at a magnification of $120 \times$ as adhesive, cohesive, or mixed. Adhesive failure (Fig. 3) refers to complete detachment between the denture base resin and a prefabricated tooth; cohesive failure (Fig. 4) refers to a complete fracture in the denture base resin or tooth; mixed failure (Fig. 5) refers to both occurring simultaneously. ${ }^{7}$ Normality of distribution was tested with the Shapiro-Wilk test. Analysis of variance (one-way ANOVA) and Tukey multiple comparison test were used to compare the obtained values among different groups of material (normal distribution). The analysis was carried out using a statistical software package (SPSS Statistics 17.0, IBM, Armonk, NY, USA) on the Windows platform. The significance level was set at $5 \%$. 


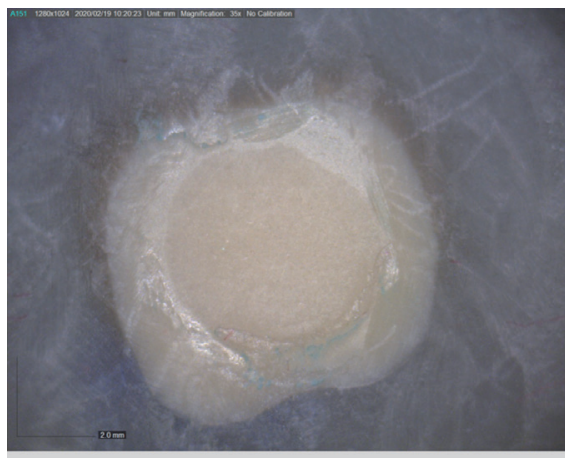

Fig. 3. Adhesive failure.

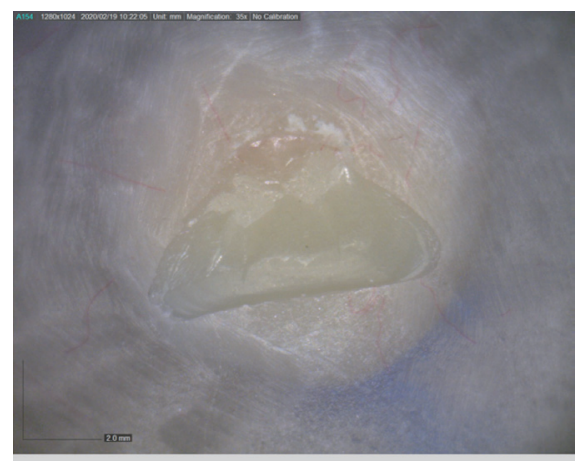

Fig. 4. Cohesive failure.

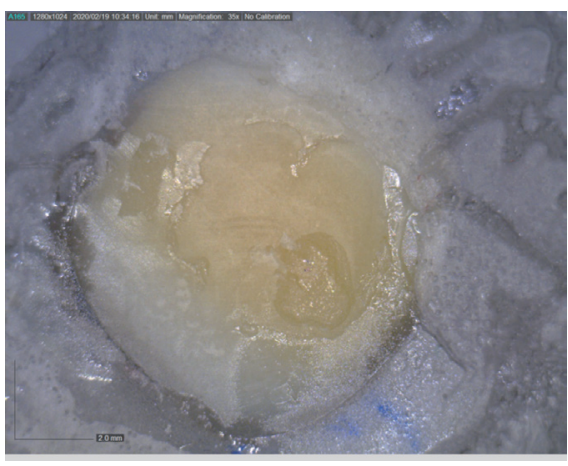

Fig. 5. Mixed failure.

\section{RESULTS}

Descriptive statistics for shear bond strength values of different groups are presented in Fig. 6. The minimal and maximal shear bond strength values (in $\mathrm{MPa}$ ) of the tested groups were 0.90 and 6.49 for group 1, 5.58 and 13.18 for group 2, 5.73 and 18.27 for group 3, 13.02 and 20.45 for group 4, 5.53 and 19.07 for group 5, 7.20 and 19.89 for group 6, 8.54 and 16.03 for group 7, 12.66 and 17.71 for group 8, 9.26 and 18.92 for group 9, and 8.28 and 22.54 for group 10.
One-way ANOVA showed significant differences in shear bond strength values among the tested groups $(P<$ .0001). The results of the Tukey post-hoc test are shown in Fig. 6. Modes of failure are presented in Table 2.

\section{DISCUSSION}

The present study investigated the shear bond strength between different types of denture base resins and different types of prefabricated and CAD/CAM (milled) denture teeth, with an emphasis on digitally produced denture base

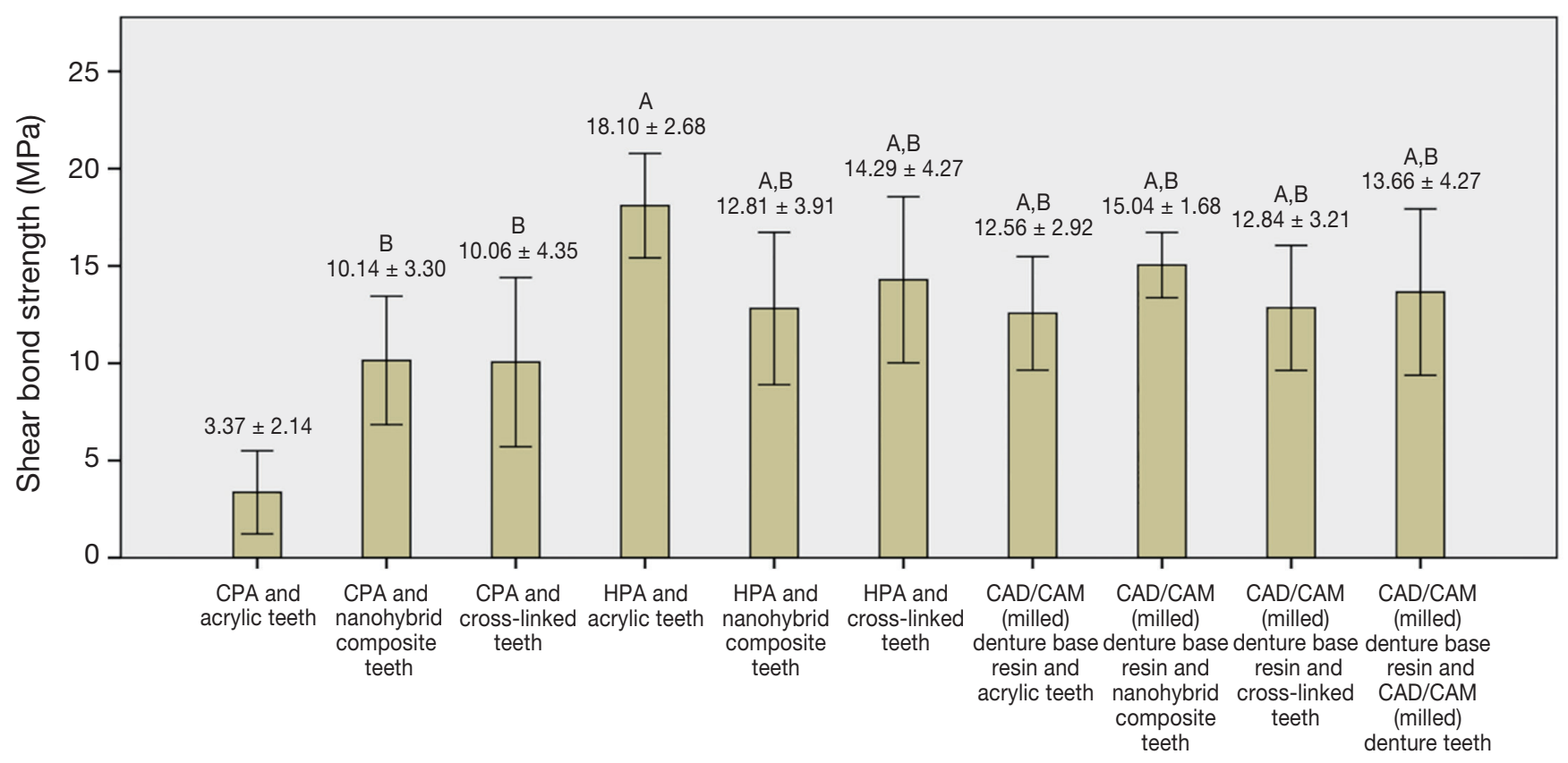

\section{Combination of materials}

Fig. 6. Means and standard deviations of shear bond strength for groups. Similar uppercase letters denote no significant differences between groups (Tukey post-hoc test, $P>$.05). CPA - cold-polymerized acrylics; HPA - heat-polymerized acrylics. 
Table 2. Number of tested groups, combination of materials, number of specimens and mode of failure

\begin{tabular}{|c|c|c|c|c|c|}
\hline Group & Combination of materials & $\mathrm{n}$ & $\begin{array}{l}\text { Adhesive } \\
\text { failure }\end{array}$ & $\begin{array}{c}\text { Cohesive } \\
\text { failure }\end{array}$ & $\begin{array}{l}\text { Mixed } \\
\text { failure }\end{array}$ \\
\hline 1 & Cold-polymerized denture base resin and acrylic teeth & 8 & 7 & - & 1 \\
\hline 2 & Cold-polymerized denture base resin and nanohybrid composite teeth & 8 & 5 & 2 & 1 \\
\hline 3 & Cold-polymerized denture base resin and cross-linked teeth & 8 & 5 & 3 & - \\
\hline 4 & Heat-polymerized denture base resin and acrylic teeth & 8 & 1 & 7 & - \\
\hline 5 & Heat-polymerized denture base resin and nanohybrid composite teeth & 8 & 2 & 6 & - \\
\hline 6 & Heat-polymerized denture base resin and cross-linked teeth & 8 & 1 & 7 & - \\
\hline 7 & CAD/CAM (milled) denture base resin and acrylic teeth & 8 & 3 & 5 & - \\
\hline 8 & CAD/CAM (milled) denture base resin and nanohybrid composite teeth & 8 & - & 8 & - \\
\hline 9 & CAD/CAM (milled) denture base resin and cross-linked teeth & 8 & 1 & 6 & 1 \\
\hline 10 & CAD/CAM (milled) denture base resin and CAD/CAM (milled) denture teeth & 8 & 3 & 5 & - \\
\hline
\end{tabular}

resins. The null hypothesis was rejected because the statistical analysis showed differences among the study groups.

Shear bond strength is the strength of a material or component against the type of yield or structural failure when the material or component fails by shear force. Since a tooth can detach from a denture base for various reasons, it is important that the shear bond strength is as high as possible. In this study, the highest shear bond strength values $(18.10 \pm 2.68 \mathrm{MPa})$ were observed in group 4 (heat-polymerized denture base resin and acrylic teeth; Fig. 6). Because acrylic teeth can chemically bond to PMMA denture base resins, ${ }^{7}$ these findings were expected, and they are comparable to the results of other studies. ${ }^{8,11}$

The results of the present study determined the lowest values in cold-polymerized denture base resins (Fig. 6). This finding is similar to previous studies, which compared the shear bond strength of heat-polymerized and cold-polymerized denture base resins with prefabricated teeth. . $^{8,11,26,28}$ Although cold-polymerized denture base resins have been promoted as an alternative to heat-polymerized ones, ${ }^{2}$ they are not capable of diffusing effectively into the denture tooth surface. According to Chung et al., ${ }^{20}$ their shear bond strength can only reach one-quarter of the strength of heatpolymerized denture base resins. The closest investigation to the present study is the investigation by Choi et al. ${ }^{9}$ These authors followed the same scientific question and compared heat-polymerized, CAD/CAM (milled), and 3D-printed denture base resins with four types of commercial denture teeth. They determined that the highest bond strength values were present in heat-polymerized denture bases, followed by CAD/CAM (milled), while 3D-printed resin showed the lowest bond strength values. The results are opposite of those of the present study, in which differences in CAD/CAM (milled) and heat-polymerized denture bases were not determined (Fig. 6). It must be considered that the study by Choi et al. ${ }^{9}$ had a different experimental design; the authors used different combinations of materials and different bond strength tests (flexural bond strength), making comparison difficult. Different adhesives are used to overcome the difficulty in achieving adequate chemical bonding, ${ }^{29}$ and their ability to bond various materials is well known. ${ }^{30,31}$ In a study by Rosca et al., ${ }^{29}$ the authors obtained adequate shear bond strength values between light-polymerized composite and PMMA using a universal adhesive. Yanikoglu et al..$^{10}$ examined the shear bond strengths of light-polymerized composites and cold-polymerized acrylics to acrylic teeth and reported that, if an adequate bonding agent is used, enhanced bonding can be attained with a composite material. In a systematic review, Mine et al. ${ }^{32}$ concluded that materials containing methyl methacrylate improved the bonding of CAD/CAM PMMA resin materials. Previous research ${ }^{10,17,32,33}$ and the present study results (Fig. 6) suggest that PMMA-based bonding material is an option for denture teeth placement that is comparable to processing with heat polymerization.

Prefabricated teeth can be attached to a 3D-printed denture base using different techniques, including bonding with a light-polymerized bonding agent ${ }^{11}$ or with cold or heat polymerization. ${ }^{19,21}$ Since attaching of prefabricated teeth to the 3D-printed denture base using cold or heat polymerization is a customary way of finishing $3 \mathrm{D}$ printed digital dentures, in the first six groups of the present study, it was also aimed to evaluate the shear strength of different types of prefabricated teeth to the 3D-printed denture base. Consequently, from the present (Fig. 6) and previous studies, ${ }^{9,11,26}$ results, it is recommended to bond 3D-printed denture base resins and prefabricated teeth with heat polymerization to obtain optimal shear bond strength values. In average, lower bond strength values are expected with prefabricated teeth bonded to cold-polymerized acrylics (Fig. 6). ${ }^{8,11,20,26,28}$ Therefore, such acrylics should be avoided when attaching prefabricated teeth to a 3D-printed denture base.

The mode of failure has been used as a measure of the performance of bonding. ${ }^{12}$ Adhesive failures have been considered the least acceptable, mixed failures acceptable, and cohesive failures perfect. ${ }^{12}$ In this study, it was found that, 
with higher shear bond strength values, higher percentages of cohesive and mixed failures were also evident, which is in accordance with a study by Akin et al. ${ }^{13} \mathrm{CAD} / \mathrm{CAM}$ (milled) and heat-polymerized denture bases had similar percentages of cohesive and mixed failures, while coldpolymerized acrylics showed mostly adhesive failures (Table 2). Similar results to our study were obtained by Jain $e t a l .^{5}$ and Neppelenbroek et al., ${ }^{6}$ who stated that the cohesive failure mode between heat-polymerized denture base resin and acrylic teeth occurred in $100 \%$ of instances. The prevalence of cohesive failures suggests that the bond strength between denture base acrylics and prefabricated teeth was higher compared with the resistance of each material alone. ${ }^{14}$

The comparison between the results of the present study and previous studies is difficult because there has been no standardization of testing techniques in the literature, as well as because of the diversity of dental materials that were used. ${ }^{2}$ With emerging technologies, there are different ways of processing and finishing removable dentures. The present study aimed to compare different types of removable denture base materials and has included 10 different combinations with different denture teeth. Still, due to inaccessibility, not every possible combination was included, which is a limitation of the present study. In future, building on the present study results, similar studies could estimate the bond strength between the 3D printed denture base resin and artificial teeth, and also determine the most favorable option for attaching teeth to an appropriate denture base.

\section{CONCLUSION}

Shear bond strength significantly depends on the selected combination of a denture base material and a denture tooth material. Materials with higher shear bond strength values (heat-polymerized resins and CAD/CAM [milled] denture base resins) show mostly cohesive and mixed modes of failure compared with cold-polymerized resins, which mainly exhibit adhesive modes of failure. Denture teeth glued to a CAD/CAM (milled) denture base using a PMMA bonding agent show similar bond strength compared with denture teeth attached to heat-polymerized denture base resin.

\section{ACKNOWLEDGMENTS}

The authors would like to thank Mrs. Maja Galović for assistance during specimen preparation, Associate Professor Jelena Dumančić for assistance with creating photos, and Associate Professor Kristina Goršeta for assistance during specimen testing.

\section{ORCID}

Vladimir Prpić bttps://orcid.org/0000-0001-6058-1503

Zdravko Schauperl bttps://orcid.org/0000-0001-7388-8555

Domagoj Glavina https://orcid.org/0000-0002-5769-6577
Amir Ćatić bttps://orcid.org/0000-0002-9332-5423

Samir Čimić https://orcid.org/0000-0002-5029-310X

\section{REFERENCES}

1. Pero AC, Scavassin PM, Nunes ÉM, Policastro VB, Giro G, Compagnoni MA. Bond strength of artificial teeth attached to a microwave-polymerized denture base resin after immersion in disinfectant solutions. J Prosthodont 2016;25:576-9.

2. Marra J, de Souza RF, Barbosa DB, Pero AC, Compagnoni MA. Evaluation of the bond strength of denture base resins to acrylic resin teeth: effect of thermocycling. J Prosthodont 2009;18:438-43.

3. Madhav GV, Raj S, Yadav N, Mudgal I, Mehta N, Tatwadiya R. Shear bond strength of acrylic teeth to acrylic denture base after different surface conditioning methods. J Contemp Dent Pract 2013;14:892-7.

4. Chittaranjan B, Taruna M, Sudheer N, Patil NS. Evaluation of shear bond strength of three different types of artificial teeth to heat cure denture base resin: an in vitro study. Indian J Dent Res 2013;24:321-5.

5. Jain G, Palekar U, Awinashe V, Mishra SK, Kawadkar A, Rahangdale T. The effect of different chemical surface treatments of denture teeth on shear bond strength: a comparative study. J Clin Diagn Res 2014;8:ZC15-8.

6. Neppelenbroek KH, Urban VM, de Oliveira DG, Porto VC, Almilhatti HJ, Campanha NH. Effect of potentially chromogenic beverages on shear bond strength of acrylic denture teeth to heat-polymerized denture base resins. J Indian Prosthodont Soc 2016;16:271-5.

7. Akin H, Tugut F, Guney U, Akar T. Shear bond strength of denture teeth to two chemically different denture base resins after various surface treatments. J Prosthodont 2014;23:152-6.

8. Patil SB, Naveen BH, Patil NP. Bonding acrylic teeth to acrylic resin denture bases: a review. Gerodontology 2006;23:1319.

9. Choi JJE, Uy CE, Plaksina P, Ramani RS, Ganjigatti R, Waddell JN. Bond strength of denture teeth to heat-cured, $\mathrm{cad} / \mathrm{cam}$ and $3 \mathrm{~d}$ printed denture acrylics. J Prosthodont 2020; 29:415-21.

10. Yanikoglu DN, Duymus DZ, Bayindir DF. Comparative bond strengths of autopolymerising denture resin and light cured composite resin to denture teeth. Int Dent J 2002;52:20-4.

11. Barbosa DB, Monteiro DR, Barão VA, Pero AC, Compagnoni MA. Effect of monomer treatment and polymerisation methods on the bond strength of resin teeth to denture base material. Gerodontology 2009;26:225-31.

12. Yoshida Y, Yoshihara K, Nagaoka N, Hayakawa S, Torii Y, Ogawa T, Osaka A, Meerbeek BV. Self-assembled nano-layering at the adhesive interface. J Dent Res 2012;91:376-81.

13. Akin H, Kirmali O, Tugut F, Coskun ME. Effects of different surface treatments on the bond strength of acrylic denture teeth to polymethylmethacrylate denture base material. Photomed Laser Surg 2014;32:512-6.

14. Andrade de Freitas SL, Brandt WC, Miranda ME, Vitti RP. Effect of thermocycling, teeth, and polymerization methods on bond strength teeth-denture base. Int J Dent 2018:2374327. 
15. Cunningham JL. Shear bond strength of resin teeth to heatcured and light-cured denture base resin. J Oral Rehabil 2000; 27:312-6.

16. Koodaryan R, Hafezeqoran A. Effect of surface treatment methods on the shear bond strength of auto-polymerized resin to thermoplastic denture base polymer. J Adv Prosthodont 2016;8:504-10.

17. Gharebagh TG, Hamedirad F, Miruzadeh K. Comparison of bond strength of acrylic, composite, and nanocomposite artificial teeth to heat-cure acrylic denture base resin. Front Dent 2019;16:166-72.

18. Prpic V, Slacanin I, Schauperl Z, Catic A, Dulcic N, Cimic S. A study of the flexural strength and surface hardness of different materials and technologies for occlusal device fabrication. J Prosthet Dent 2019;121:955-9.

19. Infante L, Yilmaz B, McGlumphy E, Finger I. Fabricating complete dentures with CAD/CAM technology. J Prosthet Dent 2014;111:351-5.

20. Chung YJ, Park JM, Kim TH, Ahn JS, Cha HS, Lee JH. 3D printing of resin material for denture artificial teeth: chipping and indirect tensile fracture resistance. Materials (Basel) 2018;11:1798.

21. Kim H, Lee D, Lee SY, Yang H, Park SW, Lim HP, Yun KD, Park C. Denture flask fabrication using fused deposition modeling three-dimensional printing. J Prosthodont Res 2020; 64:231-4.

22. IvoBase CAD Bond. Available at: http://www.ivoclarvivadent.co.uk/en-uk/p/all/4-material/ivobase-cad-bond/.

23. Vita Vionic Bond. Available at: https://www.vita-zahnfabrik. com/en/VITA-denture-teeth/Digital-prosthetics/DIGITALPROSTHETIC/VITA-VIONIC-BOND-48155,27568.html/.

24. Han SY, Moon YH, Lee J. Shear bond strength between CAD/CAM denture base resin and denture artificial teeth when bonded with resin cement. J Adv Prosthodont 2020;12: 251-8.

25. Sirisha K, Rambabu T, Shankar YR, Ravikumar P. Validity of bond strength tests: A critical review: Part I. J Conserv Dent 2014;17:305-11.

26. Barbosa DB, Barão VA, Monteiro DR, Compagnoni MA, Marra J. Bond strength of denture teeth to acrylic resin: effect of thermocycling and polymerisation methods. Gerodontology 2008;25:237-44.

27. Barbosa DB, Barão VAR, Monteiro DR, Marra J, Pero AC, Compagnoni MA. A technique for fabrication specimens for shear bond test using an embedded machine. Rev Odontol UNESP 2007;36:189-92.

28. Büyükyilmaz S, Ruyter IE. The effects of polymerization temperature on the acrylic resin denture base-tooth bond. Int J Prosthodont 1997;10:49-54.

29. Rosca B, Ramalho S, Sampaio-Fernandes JC, Portugal J. Reparability of two different CAD/CAM polymer materials using a light-cured composite and universal adhesives. Rev Port Estomatol Med Dent Cir Maxilofac 2016;57:189-96.

30. Barragan G, Chasqueira F, Arantes-Oliveira S, Portugal J. Ceramic repair: influence of chemical and mechanical surface conditioning on adhesion to zirconia. Oral Health Dent Manag 2014;13:155-8.
31. Seabra B, Arantes-Oliveira S, Portugal J. Influence of multimode universal adhesives and zirconia primer application techniques on zirconia repair. J Prosthet Dent 2014;112:1827.

32. Mine A, Kabetani T, Kawaguchi-Uemura A, Higashi M, Tajiri Y, Hagino R, Imai D, Yumitate M, Ban S, Matsumoto M, Yatani H. Effectiveness of current adhesive systems when bonding to $\mathrm{CAD} / \mathrm{CAM}$ indirect resin materials: A review of 32 publications. Jpn Dent Sci Rev 2019;55:41-50.

33. Jeong KW, Kim SH. Influence of surface treatments and repair materials on the shear bond strength of CAD/CAM provisional restorations. J Adv Prosthodont 2019;11:95-104. 